\title{
Exaggerated increase of exercise-induced pulmonary artery pressure in systemic sclerosis patients predominantly results from left ventricular diastolic dysfunction
}

\author{
Michał Ciurzyński • Piotr Bienias · Katarzyna Irzyk • \\ Maciej Kostrubiec $\cdot$ Zbigniew Bartoszewicz $\cdot$ Maria Siwicka \\ Marcin Kurzyna $\cdot$ Urszula Demkow $\cdot$ Piotr Pruszczyk
}

Received: 18 February 2013/Accepted: 21 June 2013/Published online: 4 July 2013

(c) The Author(s) 2013. This article is published with open access at Springerlink.com

\begin{abstract}
Objective High prevalence of exaggerated pulmonary artery pressure response to exercise (EPAPR) was reported in patients with systemic sclerosis (SSc). However, pathophysiology of this phenomenon has not been well defined. Therefore, we evaluated the frequency and potential aetiology of EPAPR in SSc patients.

Methods We included 85 patients (79 female, 6 male, mean age $54.3 \pm 13.9$ years) with SSc. Transthoracic echocardiography followed by exercise Doppler echocardiography (EDE) were performed. A positive EDE was defined when at least $20 \mathrm{mmHg}$ increase of tricuspid
\end{abstract}

M. Ciurzyński $(\bowtie) \cdot$ P. Bienias · K. Irzyk · M. Kostrubiec ·

P. Pruszczyk

Department of Internal Medicine and Cardiology,

Medical University of Warsaw, Warsaw, Poland

e-mail: michal.ciurzynski@wum.edu.pl

\section{Z. Bartoszewicz}

Department of Internal Medicine and Endocrinology,

Medical University of Warsaw, Warsaw, Poland

\section{Z. Bartoszewicz}

Department of Endocrinology, Warsaw Medical Research

Centre of Polish Academy of Science, Warsaw, Poland

\section{Siwicka}

Department of Dermatology, Medical University of Warsaw,

Warsaw, Poland

\section{Kurzyna}

Department of Pulmonary Circulation and Thromboembolic

Diseases, Medical Center of Postgraduate Education,

European Health Centre, Otwock, Poland

U. Demkow

Department of Laboratory Diagnostics and Clinical Immunology of Developmental Age, Medical University of Warsaw,

Warsaw, Poland regurgitation peak gradient (TRPG) was recorded. Right heart catheterization (RHC) with exercise was performed in positive EDE patients and in subjects with resting TRPG $>31 \mathrm{mmHg}$.

Results Resting TRPG $>31 \mathrm{mmHg}$ and/or positive EDE was found in 30 patients and they were referred to RHC. Finally, RHC was performed in 20 patients (16 pts resting TRPG $>31 \mathrm{mmHg}$ and 4 others normal resting TRPG and positive EDE). In 12 (60\%) of them an EPAPR with elevated pulmonary capillary wedge pressure (PCWP) was observed. Interestingly, mean left atrium (LA) diameter was greater in an EPAPR with elevated PCWP patients than in subjects with normal exercise response $(39.36 \pm 5.6$ vs. $35.53 \pm 3.48, p=0.03)$. In EPAPR with elevated PCWP group greater mean value of $\mathrm{E} / \mathrm{E}^{\prime}$ of mitral lateral annulus was observed $(7.98 \pm 3.35$ vs. $6.27 \pm 1.94$, $p=0.03)$. In the univariate logistic regression analysis increased LA diameter was significant predictor of EPAPR with elevated PCWP (OR 1.199, $95 \%$ CI 1.029-1.396, $p=0.019$ ).

Conclusions Despite very well-known risk of PAH in systemic sclerosis patients, the excessive increase of PAP during exercise is more commonly caused by left ventricular diastolic dysfunction than pulmonary arterial vasculopathy.

Keywords Scleroderma - Echocardiography $\cdot$ Pulmonary hypertension - Diastolic dysfunction

$\begin{array}{ll}\text { Abbreviations list } \\ \text { ACE-I } & \begin{array}{l}\text { Angiotensin-converting enzyme } \\ \text { inhibitors }\end{array} \\ \text { DTI } & \text { Tissue Doppler imaging } \\ \text { EDE } & \begin{array}{l}\text { Exercise Doppler echocardiography } \\ \text { EPAPR }\end{array} \\ & \begin{array}{l}\text { Exaggerated pulmonary artery pressure } \\ \text { responses to exercise }\end{array}\end{array}$




\begin{tabular}{|c|c|}
\hline $\mathrm{ESC}$ & European society of cardiology \\
\hline EUSTAR & $\begin{array}{l}\text { European Scleroderma Trial and } \\
\text { Research }\end{array}$ \\
\hline FEV1/VC & $\begin{array}{l}\text { Forced expiratory volume in one second } \\
\text { to vital capacity ratio }\end{array}$ \\
\hline FVC & Forced vital capacity \\
\hline LA & Left atrium \\
\hline LV & Left ventricle \\
\hline MAPSE & Mitral annular peak systolic excursion \\
\hline MDRD & $\begin{array}{l}\text { Modification of diet in renal disease } \\
\text { study group }\end{array}$ \\
\hline MVF & Mitral valve inflow \\
\hline NT-proBNP- N & Terminal pro-brain natriuretic peptide \\
\hline PAP & Pulmonary arterial pressure \\
\hline PCWP & Pulmonary capillary wedge pressure \\
\hline PH & Pulmonary hypertension \\
\hline RHC & Right heart catheterization \\
\hline $\mathrm{SSc}$ & Systemic sclerosis \\
\hline TAPSE & $\begin{array}{l}\text { Tricuspid annular peak systolic } \\
\text { excursion }\end{array}$ \\
\hline TRPG & Tricuspid regurgitation peak gradient \\
\hline
\end{tabular}

\section{Introduction}

Pulmonary hypertension (PH) is a well-known complication of systemic sclerosis and together with interstitial lung diseases is the leading cause of SSc-related deaths. The prevalence of pulmonary arterial hypertension in SSc patients is $7-12 \%[1,2]$. Early and proper diagnosis of pulmonary hypertension $(\mathrm{PH})$ in systemic sclerosis $(\mathrm{SSc})$ patients is very important for their outcome, because patients with already advanced, symptomatic PH usually have poor prognosis [3-6]. In one randomized controlled trial was shown that therapeutic intervention at an early stage of PH may be beneficial [7]. Recent data suggest that there is an unexpectedly high prevalence of inappropriate pulmonary artery pressure (PAP) responses to exercise in patients with SSc [8-12]. However, its clinical significance is still under discussion. According to the latest European Guidelines definition of $\mathrm{PH}$ does not include exerciseinduced PH mainly due to lack of sufficient data [3]. Some authors suggested that SSc patients with normal resting PAP and excessive exercise increase in PAP present an early stage of pulmonary arteriolar vasculopathy [13]. However, in this group of patients progressive cardiac fibrosis impairing left ventricular (LV) diastolic function was also reported $[14,15]$. Therefore, we assumed that impaired LV diastolic function present in SSc patients is responsible for exaggerated PAP responses to exercise and can lead to post-capillary hypertension.

\section{Materials and methods}

A group of 89 consecutive patients ( 82 females and 7 males, mean age $54.8 \pm 13.6$ years) with diagnosed SSc (mean disease duration $9.0 \pm 12.4$ years, range 1-45 years, median 6 years) were enrolled in this prospective study. The diagnosis of SSc was based on the American College of Rheumatology criteria [16]. Diffuse disease was found in $54(61 \%)$ patients and limited disease in the remaining 35 (39\%) patients. Clinical characterization of patients with SSc was performed according to the European Scleroderma Trial and Research (EUSTAR) recommendations [17].

We did not include patients with coronary artery disease (angina pectoris, previous myocardial infarction, ECG and/ or echocardiographic signs of myocardial ischemia), severe systemic hypertension, LV hypertrophy (intraventricular septum or posterior wall $>11 \mathrm{~mm}$ at echocardiographic examination) and with significant valvular heart disease. Restrictive LV filling at resting echocardiography with an average $\mathrm{E} / \mathrm{E}^{\prime}>13$ (or septal $\mathrm{E} / \mathrm{E}^{\prime} \geq 15$ or lateral $\mathrm{E} / \mathrm{E}^{\prime}>12$ ) was also an exclusion criterion [18]. We excluded patients with significant pulmonary dysfunction defined as forced vital capacity (FVC) and total lung capacity values $<60 \%$ predicted and/or the forced expiratory volume in one second to vital capacity ratio (FEV1/VC) $<70 \%$ predicted. We also did not include patients with significant fibrotic changes in the lung by high-resolution computed tomography (Kazerooni fibrosis score $\geq 16$ ). An impaired renal function with creatinine clearance calculated by Modification of Diet in Renal Disease Study Group (MDRD) formula below $60 \mathrm{ml} / \mathrm{min}$ was also an exclusion criterion.

As a control group we assessed 21 age and sex-matched subjects (18 females, 3 males, mean age $49.3 \pm$ 10.5 years) with similar profile of coexisting systemic hypertension and its treatment as the study group. These subjects had no data for pulmonary diseases and presented no echocardiographic evidence of structural heart disease.

All patients and control subjects gave informed consent, and the protocol of the study was approved by the local Institutional Ethics Committee (No. KB66/2006).

\section{Echocardiography}

Echocardiographic examination was performed with Philips iE 33 (Andover, Md., USA) with 2.5-3.5 MHz transducers. Using continuous-wave Doppler echocardiography, the tricuspid regurgitation peak gradient (TRPG) was calculated according to the simplified Bernoulli's equation. According to European Society of Cardiology (ESC) criteria PH was suspected when TRPG $>31 \mathrm{mmHg}$ (tricuspid regurgitant velocity $>2.8 \mathrm{~m} / \mathrm{s}$ ) [5]. In order to assess the 
right ventricular function using the one-dimensional M-mode echocardiography, the tricuspid annular peak systolic excursion (TAPSE) was measured. The LV ejection fraction (EF) was calculated according to the modified Simpson rule using apical four- and two-chamber views [19].

\section{Assessment of left ventricular diastolic function}

Mitral valve inflow (MVF) was recorded in the apical fourchamber view with Doppler gate positioned in the LV on the level of the mitral valve edges. The following parameters were evaluated: peak velocity of the early inflow phase (E), peak velocity of the atrial inflow phase (A) and E/A ratio.

Tissue Doppler imaging (DTI) was performed in the apical views to acquire mitral annular velocities. Lateral annulus early diastolic velocity (Mit $\mathrm{E}^{\prime}$ lateral) and septal annulus early diastolic velocity (Mit $\mathrm{E}^{\prime}$ septal) were measured. Moreover, mitral $\mathrm{E} / \mathrm{E}^{\prime}$ lateral and septal were calculated. $\mathrm{E} / \mathrm{E}^{\prime}>13$ (or septal $\mathrm{E} / \mathrm{E}^{\prime} \geq 15$ or lateral $\mathrm{E} / \mathrm{E}^{\prime}>12$ ) was defined as abnormal [18].

The exercise echocardiography protocol and the methodology for measuring right ventricular systolic pressure at rest and following exercise

The patient then performed a standard exercise on a treadmill according to the Bruce protocol until $85 \%$ of the maximum heart rate was achieved. The exercise was then stopped and the patient resumed the left lateral position as soon as possible. In the apical four-chamber view, using continuous-wave Doppler, the peak velocity of the tricuspid regurgitant wave was recorded and the TRPG was calculated. The TRPG was recorded within 1 min after stopping the exercise. PH was suspected when TRPG at rest exceeded $31 \mathrm{mmHg}(\mathrm{Vmax}>2.8 \mathrm{~m} / \mathrm{s})$ or increased by at least $20 \mathrm{mmHg}$ versus baseline following exercise [13]. Patients with suspicion of $\mathrm{PH}$ were referred to right heart catheter (RHC).

\section{Hemodynamics assessment of the right heart}

Cardiac catheterization was performed within 6 weeks of exercise echocardiography according to the previously described protocol [20]. The Swan-Ganz catheter was passed under fluoroscopic guidance to the pulmonary artery. The following variables were recorded: PAP (systolic, diastolic and mean), mean pulmonary capillary wedge pressure (PCWP) and mean right atrial pressure.

Cardiac output was determined by thermodilution injecting cooled saline until a variability of $<10 \%$ was achieved in three consecutive measurements. The vascular resistance values in the pulmonary and systemic circulation were calculated using typical formulas. The exercise test was performed on a cyclo ergometer in the lying position, aiming to achieve the maximum load of $125 \mathrm{~W}$. After 5 min of maximal tolerated exercise the same measurements as those at rest were performed. A special attention has been paid to the reliable measurement of PCWP. Tip of the catheter was placed in distal part of the pulmonary arterial tree and balloon was carefully filled with increasing volume of air to avoid over wedge phenomenon. The measurement was accepted, when rapid drop in PAP has been obtained and biphasic pressure curve with respiratory variation typical for wedge pressure was recorded. Digitized mean values of PCPW were used for calculations at rest and at exercise. We found it impossible to measure PCPW at exercise using breath-hold technique or extract end-expiratory values, because of high respiratory rate and important fluctuations in intrathoracic pressure.

In accordance with the ESC recommendations, $\mathrm{PAH}$ at rest was diagnosed when $\mathrm{mPAP}$ was $\geq 25 \mathrm{mmHg}$ and PCWP did not exceed $15 \mathrm{mmHg}$ [5]. Exaggerated pulmonary artery pressure response to exercise (EPAPR) with normal PCWP was identified when mPAP during exercise exceeded $30 \mathrm{mmHg}$ in the presence of normal PCWP. The venous $\mathrm{PH}$ at rest was diagnosed when mPAP at rest was $\geq 25 \mathrm{mmHg}$ and PCWP exceeded $15 \mathrm{mmHg}$ [5]. Exaggerated pulmonary artery pressure response to exercise (EPAPR) with elevated PCWP was diagnosed when mPAP during exercise exceeded $30 \mathrm{mmHg}$ and PCWP exceeded $20 \mathrm{mmHg}$ [21].

\section{Blood sampling and assays}

Fasting blood samples were collected by venipuncture, centrifuged and sera were stored at $-70{ }^{\circ} \mathrm{C}$ until assayed. The concentration of NT-proBNP was analyzed on Elecsys 2010 automatic analyzer (Roche Diagnostics, Basel, Switzerland). Serum NT-proBNP concentration higher than $125 \mathrm{pg} / \mathrm{ml}$ was regarded as abnormal as indicated by the producer.

Statistical analysis

Data characterized by a normal distribution are expressed as a mean followed by a standard deviation. Biochemical parameters are expressed both as a mean followed by a standard deviation and as a median with a range. Patients with SSc and controls were compared with Wilcoxon test depending on the character of parameters distribution. For categorical variables, the differences between the groups were compared with $\chi^{2}$ test or Fisher's exact test. Correlations between echocardiographic and biochemical variables 
were evaluated by Spearman's correlation coefficients. Logistic regression analysis was done to assess the odds ratio for abnormal exercise increase in post-capillary PAP.

An analysis was performed using a statistical software package (SAS 9.2). $p<0.05$ was considered statistically significant.

\section{Results}

None of the patients enrolled in our study had any clinical symptoms at rest suggestive for PH. Fifteen (17\%) subjects complained mild or moderate exertional dyspnoea. Due to orthopaedic conditions preventing from undergoing an adequate physical exercise $4(4.5 \%)$ patients were excluded. Finally, a total of $85 \mathrm{SSc}$ patients performed exercise test.

The general characteristics of $85 \mathrm{SSc}$ patients and control group undergoing exercise echocardiography are summarized in Table 1.

\section{Treatment}

Angiotensin-converting enzyme inhibitors (ACE-I) received $23(27 \%)$ SSc patients, angiotensin II receptor antagonists-5 (6\%), beta blockers-7 (8\%), diuretics-12 (14\%), calcium channel blockers-20 (23\%). Due to the progression of SSc $12(14 \%)$ patients received immunosuppressant agents (glucocorticoids and cyclophosphamide). We did not find significant differences in the use of the cardiovascular drugs between SSc and control group.

The main clinical, pulmonary function and serological findings of SSc patients are shown in Table 2.

\section{Echocardiographic data}

In Table 3 the echocardiographic parameters in SSc group and controls are presented.

Table 1 The general parameters in the SSc and the control groups

\begin{tabular}{llll}
\hline Parameter & $\begin{array}{l}\text { SSc patients } \\
(n=85)\end{array}$ & $\begin{array}{l}\text { Control } \\
\text { subjects } \\
(n=21)\end{array}$ & $p$ value \\
\hline Age (years) & $54.3 \pm 13.9$ & $49.3 \pm 10.5$ & 0.09 \\
$\begin{array}{l}\text { Gender (F/M), no. } \\
\text { Body surface area }\left(\mathrm{m}^{2}\right)\end{array}$ & $79 / 6$ & $18 / 3$ & 0.38 \\
$\begin{array}{l}\text { Heart rate (bpm) } \\
\begin{array}{l}\text { Blood pressure systolic } \\
\text { (mmHg) }\end{array}\end{array}$ & $73.47 \pm 9.45$ & $1.72 \pm 0.18$ & 0.7 \\
$\begin{array}{l}\text { Blood pressure diastolic } \\
(\mathrm{mmHg})\end{array}$ & $76.4 \pm 11$ & $82.3 \pm 12.21 \pm 12.38$ & 0.3 \\
$\begin{array}{l}\text { Systemic hypertension } \\
(\%)\end{array}$ & $25(29 \%)$ & $6(29 \%)$ & 0.02 \\
\hline
\end{tabular}

Table 2 Clinical, pulmonary function and serological data of $85 \mathrm{SSc}$ patients

\begin{tabular}{lll}
\hline Characteristics & Mean & Median, range \\
\hline Disease duration (years) & $9.0 \pm 12.4$ & $5.0(1-25)$ \\
Rodnan score & $6.4 \pm 6.7$ & $4.0(1-35)$ \\
FVC, $\%$ predict & $100.4 \pm 18.3$ & \\
$\mathrm{FEV}_{1}, \%$ predict & $94.7 \pm 19.7$ & \\
FEV $_{1} / \mathrm{FVC}, \%$ predict & $79.8 \pm 8.2$ & \\
TLC, $\%$ predict $_{\text {DLCO, \% predict }(n=59)}$ & $70.7 \pm 19.1$ & \\
Autoantibodies & No & $\%$ \\
ANA positive & 79 & 93 \\
ACA positive & 28 & 33 \\
Anti- Topo I & 40 & 48 \\
\hline
\end{tabular}

$F V C$ forced vital capacity, FEV1 forced expiratory volume in $1 \mathrm{~s}$, $T L C$ total lung capacity, $D L C O$ carbon monoxide diffusing capacity

Table 3 Echocardiographic parameters in SSc patients and controls

\begin{tabular}{lccl}
\hline Variables & $\begin{array}{l}\text { SSc patients } \\
(n=85)\end{array}$ & $\begin{array}{l}\text { Controls } \\
(n=21)\end{array}$ & $p$ value \\
\hline EF $(\%)$ & $65 \pm 5.1$ & $67 \pm 2.52$ & 0.01 \\
LA & $32.3 \pm 4.52$ & $31.1 \pm 3.46$ & 0.53 \\
RV/LV 4 chambers & $0.73 \pm 0.12$ & $0.66 \pm 0.08$ & 0.01 \\
TAPSE (mm) & $22.2 \pm 3.23$ & $24.14 \pm 2.37$ & 0.01 \\
MAPSE (mm) & $15.4 \pm 2.4$ & $16.3 \pm 1.8$ & 0.05 \\
Mitral E/A & $0.96 \pm 0.3$ & $1.2 \pm 0.3$ & 0.002 \\
Mit E/E' lateral mitral & $7.55 \pm 2.85$ & $6.87 \pm 2.3$ & 0.4 \\
$\quad$ & & &
\end{tabular}

$E F$ ejection fraction, $L A$ left atrium, $R V$ right ventricle, $L V$ left ventricle, TAPSE tricuspid annulus plane systolic excursion, MAPSE mitral annulus plane systolic excursion

The SSc patients presented lower mean value of mitral E/A. We did not find significant differences between the mean value of LA diameter and $\mathrm{E} / \mathrm{E}^{\prime}$.

The main parameters recorded before and after exercise test in SSc patients and controls are shown in Table 4.

The mean resting and exercise TRPG values and $\Delta$ TRPG were significantly higher in SSc patients than in controls.

Significant correlations between exercise TRPG and echocardiographic indices are listed in Table 5.

Exercise echocardiography

Thirty $(35 \%)$ patients with TRPG exceeding $31 \mathrm{mmHg}$ at rest and/or an exercise increase in TRPG $>20 \mathrm{mmHg}$ were referred for RHC. Eight refused to undergo the procedure, one patient could not performed the procedure due to a worsening of general condition and one 
Table 4 The main parameters before and after exercise test in SSc and controls

\begin{tabular}{lccc}
\hline Parameter & SSc $(\mathrm{n}=85)$ & $\begin{array}{l}\text { Controls } \\
(\mathrm{n}=21)\end{array}$ & P value \\
\hline HR (1/min) & $84.4 \pm 17.3$ & $85.3 \pm 17.2$ & 0.68 \\
Max exercise HR (1/min) & $152.8 \pm 22.9$ & $165.3 \pm 11.7$ & 0.01 \\
Workload (METS) & $8.5 \pm 2.66$ & $10.91 \pm 2.89$ & 0.0008 \\
HR max (\%) & $93.3 \pm 13.8$ & $96.6 \pm 5.3$ & 0.5 \\
Resting TRPG (mmHg) & $26.9 \pm 6.3$ & $17.8 \pm 4.1$ & $<0.0001$ \\
Exercise TRPG (mmHg) & $39.0 \pm 11.1$ & $22.4 \pm 8.4$ & $<0.0001$ \\
$\Delta$ TRPG (mmHg) & $12.5 \pm 8.1$ & $7.6 \pm 4.5$ & 0.02 \\
\hline
\end{tabular}

$T R P G$ tricuspid regurgitant peak gradient

Table 5 Significant correlations between exercise TRPG and echocardiographic parameters

\begin{tabular}{lcc}
\hline Parameter & $r$ & $p$ \\
\hline LA & 0.4 & 0.001 \\
MAPSE & -0.33 & 0.008 \\
E' Lateral mitral annulus (cm/sek) $_{\text {Mit E/E' Lateral mitral annulus }}$ & -0.31 & 0.01 \\
& 0.3 & 0.01 \\
\hline
\end{tabular}

Moreover the mean value of $\Delta$ TRPG correlates with LA diameter $(r=0.33, p=0.008)$

patient died due to bleeding from oesophageal varices while awaiting the procedure. Finally, RHC was performed in 20 patients ( 16 pts resting TRPG $>31 \mathrm{mmHg}$ and four with normal resting TRPG and EPAPR). In 12
$(60 \%)$ of them an EPAPR with elevated PCWP was observed (mean exercise mPAP $41.8 \pm 13.2 \mathrm{mmHg}$, mean exercise PCWP $25.1 \pm 4.8 \mathrm{mmHg}$ ). In remaining two PAH, one pulmonary venous hypertension and five pts an EPAPR with normal PCWP was diagnosed (Fig. 1). In all four patients with normal resting TRPG and EPAPR, elevated PCWP during exercise was observed.

Parameters obtained during RHC in SSc patients are listed in Table 6.

In Table 7 clinical, echocardiographic and biochemical parameters in SSc patients with EPAPR with elevated PCWP and in the group of normal resting end exercise TRPG are listed.

The mean LA diameter was significantly increased in SSc patients with EPAPR with elevated PCWP than in subjects with normal PAP values. Also the mean value of $\mathrm{E} / \mathrm{E}^{\prime}$ was higher in the former.

In the univariate logistic regression analysis we identified parameters that predicted EPAPR with elevated PCWP (Table 8).

\section{Discussion}

Some data underline that an excessive increase in PAP during exercise cannot be regarded as the norm [22, 23]. It was even postulated that this is an early preclinical stage of $\mathrm{PH}$. Moreover, there are also reports showing beneficial effects of bosentan treatment in asymptomatic patients, but with excessive increase in PAP during exercise [24]. Steen
Fig. 1 Qualification of patients for right heart catheterization;

TTE transthoracic

echocardiography, TRPG

tricuspid regurgitation peak

gradient, $R H C$ right heart catheterization, $P A H$ pulmonary arterial hypertension, $P H$ pulmonary hypertension, $P A P$ pulmonary artery pressure
89 SSc patients

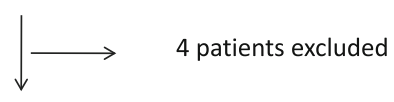

85 patients resting and exercise TTE
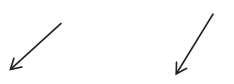

9 pts. resting TRPG > $31 \mathrm{mmHg}$, normal exercise TRPG

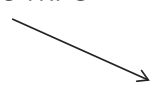

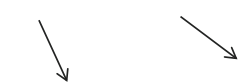

8 pts. normal resting exercise $\begin{array}{ll}\mathrm{mmHg} \text { and increase of }> & \text { TRPG and increase of }> \\ 20 \mathrm{mmHg} \text { during exercise } & 20 \mathrm{mmHg} \text { during }\end{array}$ $\begin{array}{ll}\mathrm{mmHg} \text { and increase of }> & \text { TRPG and increase } \\ 20 \mathrm{mmHg} \text { during exercise } & 20 \mathrm{mmHg} \text { during }\end{array}$

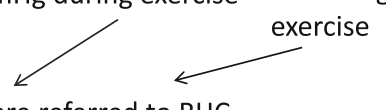

55 pts normal resting and exercise TRPG

30 pts were referred to $\mathrm{RHC}$
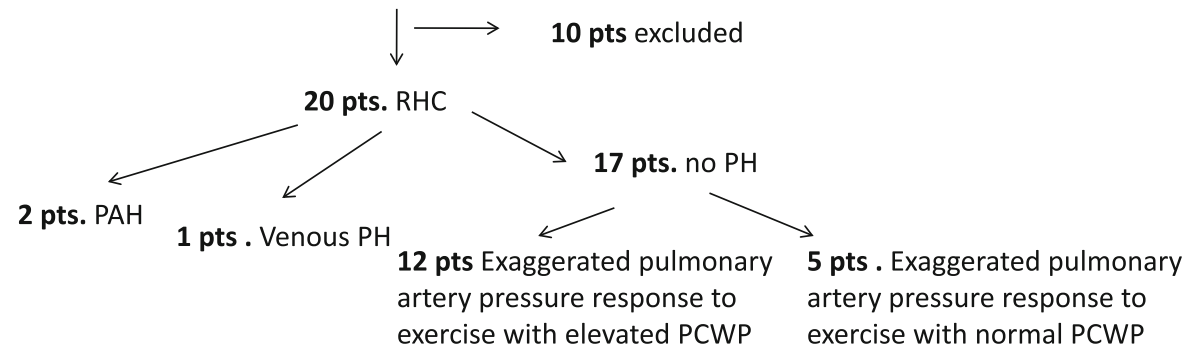
Table 6 RHC parameters in SSc patients

\begin{tabular}{lcccc}
\hline Parameter $(n=20)$ & Mean & \pm SD & Median & Range \\
\hline s PAP (mmHg) & 33.2 & 6.6 & 32.5 & $23.0-48.0$ \\
m PAP (mmHg) & 21.1 & 4.2 & 20.5 & $15.0-29.0$ \\
s PAP exercise (mmHg) & 59.7 & 18.8 & 55.0 & $38.0-115.0$ \\
m PAP exercise (mmHg) & 43.0 & 12.7 & 41.0 & $30.0-82.0$ \\
PVR (Wood U) & 2.02 & 0.9 & 1.79 & $1.07-4.46$ \\
PCWP (mmHg) & 11.2 & 3.4 & 10.5 & $7.0-20.0$ \\
PCWP exercise (mmHg) & 22.6 & 6.1 & 23.0 & $17.0-32.0$ \\
\hline
\end{tabular}

$S P A P$ systolic pulmonary artery pressure, $m P A P$ mean pulmonary artery pressure, $P V R$ pulmonary vascular resistance, $P C W P$ pulmonary capillary wedge pressure

Table 7 Clinical, echocardiographic and biochemical parameters in patients with EPAPR with elevated PCWP and in normal resting end exercise TRPG

\begin{tabular}{llll}
\hline Parameter & $\begin{array}{l}\text { EPAPR with } \\
\text { elevated PCWP } \\
(n=12)\end{array}$ & $\begin{array}{l}\text { Normal TRPG at } \\
\text { rest end during } \\
\text { exercise }(n=55)\end{array}$ & $p$ value \\
\hline Age & $59.6 \pm 7.9$ & $51.6 \pm 13.3$ & 0.03 \\
LA $(\mathrm{mm})$ & $39.36 \pm 5.6$ & $35.53 \pm 3.48$ & 0.03 \\
TAPSE $(\mathrm{mm})$ & $19.86 \pm 3.02$ & $22.26 \pm 2.75$ & 0.01 \\
MAPSE (mm) & $14.6 \pm 1.63$ & $15.62 \pm 1.98$ & 0.05 \\
E/E' mitral annulus & $7.98 \pm 3.35$ & $6.27 \pm 1.94$ & 0.03 \\
$\begin{array}{l}\text { NT-proBNP } \\
\quad \text { pg/ml)* }\end{array}$ & $\begin{array}{l}\text { Median, range } \\
130.8,57-2195\end{array}$ & $80.8,14.07-584.4$ & 0.01 \\
\hline
\end{tabular}

$T R P G$ tricuspid regurgitant peak gradient

* Wilcoxon test

Table 8 Parameters that increase the chance of EPAPR with elevated PCWP

\begin{tabular}{llll}
\hline Parameter & OR & $95 \%$ CI & P value \\
\hline TAPSE, 1 mm decrease & 1.386 & $1.074-1.788$ & 0.012 \\
LA diameter, 1 mm increase & 1.199 & $1.029-1.396$ & 0.019 \\
Age, 1 year increase & 1.06 & $1.002-1.121$ & 0.04 \\
\hline
\end{tabular}

TAPSE, LA diameter, and patients' age are the parameters that increase the chance of EPAPR with elevated PCWP

and colleagues [13] evaluated 54 patients with SSc who underwent exercise echocardiography. They showed increase in exercise systolic PAP greater than $20 \mathrm{mmHg}$ in $44 \%$ of them. Also, Alkotob et al. [25] found an increase in exercise systolic PAP in $46 \%$ of the 65 patients with SSc. Moreover, in a paper published by Pignone et al. [26] authors showed exertional increase in systolic PAP above $40 \mathrm{mmHg}$ in $18(67 \%)$ of 27 patients with SSc. In a recently published paper Gargani et al. [12] exercise Doppler echocardiography revealed significant exerciseinduced increase in PAP in $69(42 \%)$ among 164 SSc patients with normal resting PAP. Exercise Doppler echocardiography is useful not only in patients with SSc but also in another population. Ha et al. [27] examined during exercise echocardiography 396 patients with normal left ventricular systolic function. They revealed that 135 $(35 \%)$ of them had systolic PAP $>50 \mathrm{mmHg}$ and it was associated with $\mathrm{E} / \mathrm{E}^{\prime}$ ratio.

Using standard rest and exercise echocardiography we identified 30 patients with possible PH. Finally, RHC was performed in 20 patients. Of these, four $(20 \%)$ patients were qualified to the hemodynamic study because of the excessive increase in PAP during exercise, with normal resting values of TRPG. During the RHC $12(60 \%)$ patients showed an EPAPR with elevated PCWP, while only in two PAH was eventually diagnosed. Based on these observations, it seems that Doppler echocardiography is a useful method to identify abnormal exercise-increased PAP in patients with SSc. However, to determine the type of $\mathrm{PH}$ requires cardiac catheterization. Only limited evidence indicates that LV diastolic dysfunction may be the key mechanism responsible for the inappropriate exerciseincreased PAP. Kovacs and colleagues [9] performed echocardiographic exercise test in 52 patients with connective tissue disease (26 patients with SSc). In 26 patients, despite normal values of systolic PAP at rest, exercise systolic PAP was increased up to $>40 \mathrm{mmHg}$. Twenty-one patients underwent RHC, which confirmed the normal systolic PAP at rest and exercise systolic PAP increased to $>40 \mathrm{mmHg}$ in 19 of them. Of these eight cases during RHC had elevated PCWP $>20 \mathrm{mmHg}$. Saggar et al. [28] reported a group of $57 \mathrm{SSc}$ patients who had normal resting hemodynamics and underwent subsequent exercise RHC. An inappropriate exercise-induced venous increase in PAP was reported in $12(21 \%)$ of them. D'Alto et al. [8] evaluated 172 patients with SSc without $\mathrm{PH}$ and without significant LV diastolic dysfunction $\left(\mathrm{E} / \mathrm{E}^{\prime}<15\right)$. In the $\mathrm{SSc}$ group authors found significantly higher mean value of resting systolic PAP and systolic PAP recorded after exercise. Interestingly, in patients with impaired diastolic function (the lowest quartile of the values of $\mathrm{E}^{\prime} / \mathrm{A}^{\prime}$ ) the average value of systolic PAP recorded after exercise was significantly higher than in subjects with preserved diastolic function (the highest quartile of the values of $\left.\mathrm{E}^{\prime} / \mathrm{A}^{\prime}\right)(p=0.015)$. In recently published paper, Hager et al. [29] performed RHC in $173 \mathrm{SSc}$ patients when resting echocardiographic PAP were $<40$ but $>40 \mathrm{mmHg}$ after exercise. LV diastolic dysfunction was diagnosed in 47 patients. Our findings are consistent with observations by D'Alto and Hager et al. Moreover, we observed significant correlations between exercise TRPG and echocardiographic indices of LV diastolic dysfunction in SSc patients. The mean value of exercise TRPG significantly positively correlated with the $\mathrm{LA}$ dimension, the $\mathrm{E} / \mathrm{E}^{\prime}$ lateral mitral annulus ratio and negatively with a mean E' lateral mitral annulus velocity. 
We have also demonstrated a positive correlation between the change of TRPG and LA dimension. These correlations indicate a potential link between rest and exercise TRPG and an impaired LV relaxation. We tried to define parameters potentially useful for differentiating patients with EPAPR with elevated PCWP. Thus, this group was characterized by significantly higher mean LA dimension and greater value of the $\mathrm{E} / \mathrm{E}$ ' lateral mitral annulus ratio. These observations may support the hypothesis that diastolic dysfunction is one of the major causes of EPAPR with elevated PCWP. It seems that progressive diastolic dysfunction does not impair PH at rest; however, it can contribute to an abnormal EPAPR with elevated PCWP. Moreover, there are evidences that serum NT-proBNP level may be useful for detection of LV diastolic dysfunction [30]. In our SSc patients with EPAPR with elevated PCWP we have found significantly higher concentrations of serum NT-proBNP level, suggesting neurohormonal activation. In univariate, logistic regression analysis we identified factors that increase the chance of EPAPR with elevated PCWP, such as LA diameter $(1.199,95 \%$ CI 1.029-1.396, $p=0.019)$, confirming the importance of diastolic dysfunction. Our study is one of the first to show that among SSc patients exaggerated pulmonary artery pressure responses to exercise is predominantly caused by impaired LV relaxation.

\section{Study limitations}

Eight SSc patients had not consented to RHC which may have influenced the results. Moreover, RHC was performed within 6 weeks after exercise echocardiography which might have resulted in changes of hemodynamic status of patients during awaiting the procedure. On the other hand, the clinical condition of patients while awaiting the RHC was stable and drug treatment was not modified.

The control group was 5 years younger than the $\mathrm{SSc}$ group $(54.3 \pm 13.9$ vs. $49.3 \pm 10.5$ years $)$. Although the difference was not significant $p=0.09$.

\section{Conclusions}

Despite very well-known risk of PAH in systemic sclerosis patients, the excessive increase of PAP during exercise is more commonly caused by left ventricular diastolic dysfunction than pulmonary arterial vasculopathy.

Acknowledgments This study was partially supported by grant NCN, UMO-2012/07/N/NZ5/01647.

Conflict of interest Dr Michał Ciurzyński, Dr Piotr Bienias, Dr Katarzyna Irzyk, Dr Maciej Kostrubiec, Dr Zbigniew Bartoszewicz, Dr Maria Siwicka, Prof Marcin Kurzyna, Prof Urszula Demkow and Prof Piotr Pruszczyk have no financial/nonfinancial disclosures and no conflicts of interest.
Open Access This article is distributed under the terms of the Creative Commons Attribution License which permits any use, distribution, and reproduction in any medium, provided the original author(s) and the source are credited.

\section{References}

1. Hachulla E, Gressin V, Guillevin L, Carpentier P, Diot E, Sibilia $\mathbf{J}$ et al (2005) Early detection of pulmonary arterial hypertension in systemic sclerosis: a French nationwide prospective multicenter study. Arthritis Rheum 52(12):3792-3800

2. Mukerjee D, St GD, Coleiro B, Knight C, Denton CP, Davar J et al (2003) Prevalence and outcome in systemic sclerosis associated pulmonary arterial hypertension: application of a registry approach. Ann Rheum Dis 62(11):1088-1093

3. Chung L, Liu J, Parsons L, Hassoun PM, McGoon M, Badesch DB et al (2010) Characterization of connective tissue diseaseassociated pulmonary arterial hypertension from REVEAL: identifying systemic sclerosis as a unique phenotype. Chest 138(6):1383-1394

4. Fisher MR, Mathai SC, Champion HC, Girgis RE, HoustenHarris T, Hummers L et al (2006) Clinical differences between idiopathic and scleroderma-related pulmonary hypertension. Arthritis Rheum 54(9):3043-3050

5. Galie N, Hoeper MM, Humbert M, Torbicki A, Vachiery JL, Barbera JA et al (2009) Guidelines for the diagnosis and treatment of pulmonary hypertension: the task force for the diagnosis and treatment of pulmonary hypertension of the European society of cardiology (ESC) and the European respiratory Society (ERS), endorsed by the International Society of heart and lung transplantation (ISHLT). Eur Heart J 30(20):2493-2537

6. McLaughlin VV, Archer SL, Badesch DB, Barst RJ, Farber HW, Lindner JR et al (2009) ACCF/AHA 2009 expert consensus document on pulmonary hypertension a report of the American college of cardiology foundation task force on expert consensus documents and the American heart association developed in collaboration with the American college of chest physicians; American thoracic society, Inc. and the pulmonary hypertension association. J Am Coll Cardiol 53(17):1573-1619

7. Galie N, Rubin L, Hoeper M, Jansa P, Al-Hiti H, Meyer G et al (2008) Treatment of patients with mildly symptomatic pulmonary arterial hypertension with bosentan (EARLY study): a doubleblind, randomised controlled trial. Lancet 371(9630):2093-2100

8. D'Alto M, Ghio S, D'Andrea A, Pazzano AS, Argiento P, Camporotondo $\mathrm{R}$ et al (2011) Inappropriate exercise-induced increase in pulmonary artery pressure in patients with systemic sclerosis. Heart 97(2):112-117

9. Kovacs G, Maier R, Aberer E, Brodmann M, Scheidl S, Hesse C et al (2010) Assessment of pulmonary arterial pressure during exercise in collagen vascular disease: echocardiography versus right-sided heart catheterization. Chest 138(2):270-278

10. Reichenberger F, Voswinckel R, Schulz R, Mensch O, Ghofrani HA, Olschewski $\mathrm{H}$ et al (2009) Non-invasive detection of early pulmonary vascular dysfunction in scleroderma. Respir Med 103(11):1713-1718

11. Callejas-Rubio JL, Moreno-Escobar E, de la Fuente PM, Perez LL, Fernandez RR, Sanchez-Cano D et al (2008) Prevalence of exercise pulmonary arterial hypertension in scleroderma. J Rheumatol 35(9):1812-1816

12. Gargani L, Pignone A, Agoston G, Moreo A, Capati E, Badano LP et al (2013) Clinical and echocardiographic correlations of exercise-induced pulmonary hypertension in systemic sclerosis: a multicenter study. Am Heart J 165(2):200-207 
13. Steen V, Chou M, Shanmugam V, Mathias M, Kuru T, Morrissey $\mathrm{R}$ (2008) Exercise-induced pulmonary arterial hypertension in patients with systemic sclerosis. Chest 134(1):146-151

14. Hachulla AL, Launay D, Gaxotte V, de GP, Lamblin N, Devos P et al (2009) Cardiac magnetic resonance imaging in systemic sclerosis: a cross-sectional observational study of 52 patients. Ann Rheum Dis 68(12):1878-1884

15. Meune C, Avouac J, Wahbi K, Cabanes L, Wipff J, Mouthon L et al (2008) Cardiac involvement in systemic sclerosis assessed by tissue-doppler echocardiography during routine care: a controlled study of 100 consecutive patients. Arthritis Rheum 58(6):1803-1809

16. (1980) Preliminary criteria for the classification of systemic sclerosis (scleroderma) Subcommittee for scleroderma criteria of the American Rheumatism Association Diagnostic and Therapeutic Criteria Committee. Arthritis Rheum 23(5):581-90

17. Valentini G, Bencivelli W, Bombardieri S, D’Angelo S, Della RA, Silman AJ et al (2003) European scleroderma study group to define disease activity criteria for systemic sclerosis III. Assessment of the construct validity of the preliminary activity criteria. Ann Rheum Dis 62(9):901-903

18. Nagueh SF, Appleton CP, Gillebert TC, Marino PN, Oh JK, Smiseth OA et al (2009) Recommendations for the evaluation of left ventricular diastolic function by echocardiography. Eur $\mathbf{J}$ Echocardiogr 10(2):165-193

19. Feigenbaum H, Armstrong WF, Ryan T (2005) Feigenbaum's echocardiography, 6th edn. Lippincott, Williams and Wilkins, Philadelphia

20. Ciurzynski M, Bienias P, Irzyk K, Rymarczyk Z, Kostrubiec M, Szewczyk A et al (2011) Usefulness of echocardiography in the identification of an excessive increase in pulmonary arterial pressure in patients with systemic sclerosis. Kardiol Pol 69(1): 9-15

21. Naeije R, Melot C, Niset G, Delcroix M, Wagner PD (1993) Mechanisms of improved arterial oxygenation after peripheral chemoreceptor stimulation during hypoxic exercise. J Appl Physiol 74(4):1666-1671
22. Bae S, Saggar R, Bolster MB, Chung L, Csuka ME, Derk C et al. (2012) Baseline characteristics and follow-up in patients with normal hemodynamics versus borderline mean pulmonary arterial pressure in systemic sclerosis: results from the PHAROS registry. Ann Rheum Dis 71(8): 1335-1342

23. Tolle JJ, Waxman AB, Van Horn TL, Pappagianopoulos PP, Systrom DM (2008) Exercise-induced pulmonary arterial hypertension. Circulation 118(21):2183-2189

24. Yagi S, Akaike M, Iwase T, Kusunose K, Niki T, Yamaguchi K et al (2010) Bosentan ameliorated exercise-induced pulmonary arterial hypertension complicated with systemic sclerosis. Intern Med 49(21):2309-2312

25. Alkotob ML, Soltani P, Sheatt MA, Katsetos MC, Rothfield N, Hager WD et al (2006) Reduced exercise capacity and stressinduced pulmonary hypertension in patients with scleroderma. Chest 130(1):176-181

26. Pignone A, Mori F, Pieri F, Oddo A, Galeota G, Fiori G et al (2007) Exercise doppler echocardiography identifies pre clinic asymptomatic pulmonary hypertension in systemic sclerosis. Ann N Y Acad Sci 1108:291-304

27. Ha JW, Choi D, Park S, Shim CY, Kim JM, Moon SH et al (2009) Determinants of exercise-induced pulmonary hypertension in patients with normal left ventricular ejection fraction. Heart 95(6):490-494

28. Saggar R, Khanna D, Furst DE, Shapiro S, Maranian P, Belperio JA et al (2010) Exercise-induced pulmonary hypertension associated with systemic sclerosis: four distinct entities. Arthritis Rheum 62(12):3741-3750

29. Hager WD, Collins I, Tate JP, Azrin M, Foley R, Lakshminarayanan S et al. (2012) Exercise during cardiac catheterization distinguishes between pulmonary and left ventricular causes of dyspnea in systemic sclerosis patients. Clin Respir J [Epub ahead of print]

30. Tschope C, Kasner M, Westermann D, Gaub R, Poller WC, Schultheiss HP (2005) The role of NT-proBNP in the diagnostics of isolated diastolic dysfunction: correlation with echocardiographic and invasive measurements. Eur Heart J 26(21):2277-2284 